\title{
EXPLORING SOUTH AFRICAN PRESERVICE TEACHERS' CONCEPTUAL UNDERSTANDING OF LIGHT PHENOMENA
}

\author{
Sam Ramaila \\ Department of Science and Technology Education, University of Johannesburg (South Africa)
}

\begin{abstract}
The wave and particle nature of light poses considerable instructional challenges to both teachers and learners in diverse educational settings. Developing a meaningful conceptual understanding of the wave and particle nature of light is a key requirement for demystifying the complex nature of various optical phenomena. The study adopted an exploratory descriptive survey design and involved purposively selected South African preservice Physical Sciences as participants. Preservice Physical Sciences teachers' conceptual understanding of light phenomena was explored through the administration of the Light Phenomena Conceptual Assessment (LPCA) inventory. The key findings of the study revealed that preservice Physical Sciences teachers exhibited conceptual hurdles in relation to light phenomena such as reflection, refraction, total internal reflection and light scattering. The prevalence of these conceptual hurdles can partly be attributed to pervasive knowledge gaps manifested as a result of deficient instructional strategies adopted to demystify complex nature of light phenomena. Theoretical implications for initial teacher education are discussed.
\end{abstract}

Keywords: Teacher education, light phenomena, instructional strategies.

\section{Introduction}

Development of meaningful conceptual understanding is a key requirement for adequate remediation of prevailing misconceptions associated with complex scientific phenomena. The wave and particle nature of light poses considerable instructional challenges to both teachers and learners in diverse instructional settings. Research has demonstrated that students may know about theories of light but still fail to interpret the interference that results from the wave nature of light (Sengoren, 2010). The navigation of these instructional challenges requires teachers to adopt nuanced and innovative pedagogic approaches to demystify the complex nature of light phenomena. Commensurate with this key strategic imperative, this study explored South African preservice Physical Sciences teachers' conceptual understanding of light phenomena with a view to glean insight into the nature of their baseline knowledge of various optical phenomena.

\section{Methodology}

South African preservice Physical Sciences teachers' conceptual understanding of light phenomena was explored through the administration of the Light Phenomena Conceptual Assessment (LPCA) inventory developed by Ndihokubwayo, Uwamahoro, Ndayambaje and Ralph (2020) as part of a survey. The empirical investigation involved 50 purposively selected $4^{\text {th }}$ year Bachelor of Education preservice Physical Sciences teachers. The cohort had already completed a physics module when the LPCA inventory was administered. In addition, the participants had been afforded opportunities to perform work integrated learning at schools during the preceding years of their professional training.

\section{Results}

Table 1 below provides participants' responses to the various items of the LPCA inventory. 
Table 1. Participants' responses to the various items of the LPCA inventory.

\begin{tabular}{|c|c|c|c|c|}
\hline & $\mathrm{A}(\%)$ & B (\%) & $\mathrm{C}(\%)$ & $\mathrm{D}(\%)$ \\
\hline 1 & & & 79 & 21 \\
\hline 2 & 5 & 69 & 26 & \\
\hline 3 & 11 & 42 & 32 & 15 \\
\hline 4 & 26 & 58 & 16 & \\
\hline 5 & 5 & 79 & 11 & 5 \\
\hline 6 & 11 & 32 & 37 & 21 \\
\hline 7 & 26 & 37 & 16 & 21 \\
\hline 8 & 37 & 26 & 21 & 11 \\
\hline 9 & 37 & 32 & 21 & 11 \\
\hline 10 & 21 & 42 & 26 & 11 \\
\hline 11 & & 32 & 53 & 16 \\
\hline 12 & 11 & 26 & 47 & 11 \\
\hline 13 & 16 & 37 & 37 & 11 \\
\hline 14 & 16 & 26 & 37 & 21 \\
\hline 15 & 16 & 47 & 11 & 26 \\
\hline 16 & 42 & 21 & 11 & 26 \\
\hline 17 & 11 & 21 & 37 & 32 \\
\hline 18 & 21 & 32 & 16 & 32 \\
\hline 19 & 16 & 37 & 37 & 11 \\
\hline 20 & 26 & 26 & 21 & 26 \\
\hline 21 & 16 & 37 & 26 & 21 \\
\hline 22 & 32 & 42 & 5 & 16 \\
\hline 23 & 21 & 21 & 32 & 26 \\
\hline 24 & 21 & 21 & 16 & 32 \\
\hline 25 & 11 & 42 & 32 & 16 \\
\hline 26 & 21 & 21 & 26 & 32 \\
\hline 27 & 21 & 21 & 32 & 26 \\
\hline 28 & 32 & 16 & 32 & 21 \\
\hline 29 & 11 & 53 & 37 & \\
\hline 30 & 11 & 53 & 5 & 32 \\
\hline
\end{tabular}

Participants' distribution of responses to the questionnaire is depicted in Figure 1 below. The preservice teachers provided a variety of responses which painted a grim picture about their conceptual understanding and baseline knowledge of light phenomena. Optics is a vast conceptual area in physics and the need to foster meaningful conceptual understanding to promote preservice teachers' mastery experiences is paramount. This key imperative is also applicable to other concomitant conceptual areas in physics as a key knowledge domain.

Figure 1. Distribution of responses.

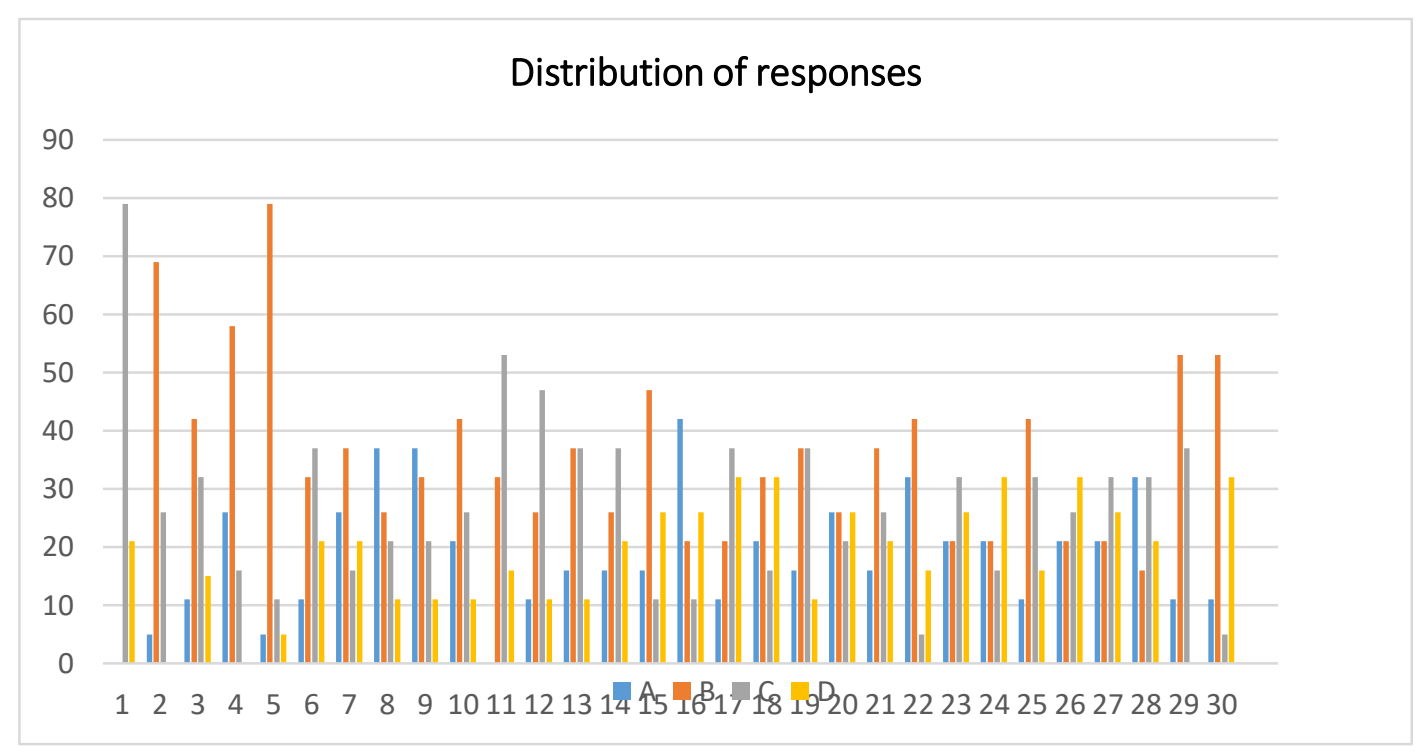


The participants' overall performance on each question is illustrated in Figure 2 below. Satisfactory overall performance was demonstrated in relation to items 1, 2, 5, 29 and 30. 79\% of the respondents provided the correct answer (C) for item 1 ("Why do we see things"). 69\% of the respondents provided the correct answer (B) for item 2 ("Why can we not see things in the dark of night"). 79\% of the respondents provided the correct answer (B) for item 5 ("Sunlight can be used to tell time. How would your image appear at 12:00 0' clock when standing outside the classroom on a hot day?"). The participants demonstrated dismal overall performance in other items pertaining to the LPCA inventory which evaluated conceptual understanding of light phenomena such as reflection, refraction, total internal reflection and light scattering.

Figure 2. Overall performance on each item of the LPCA inventory.

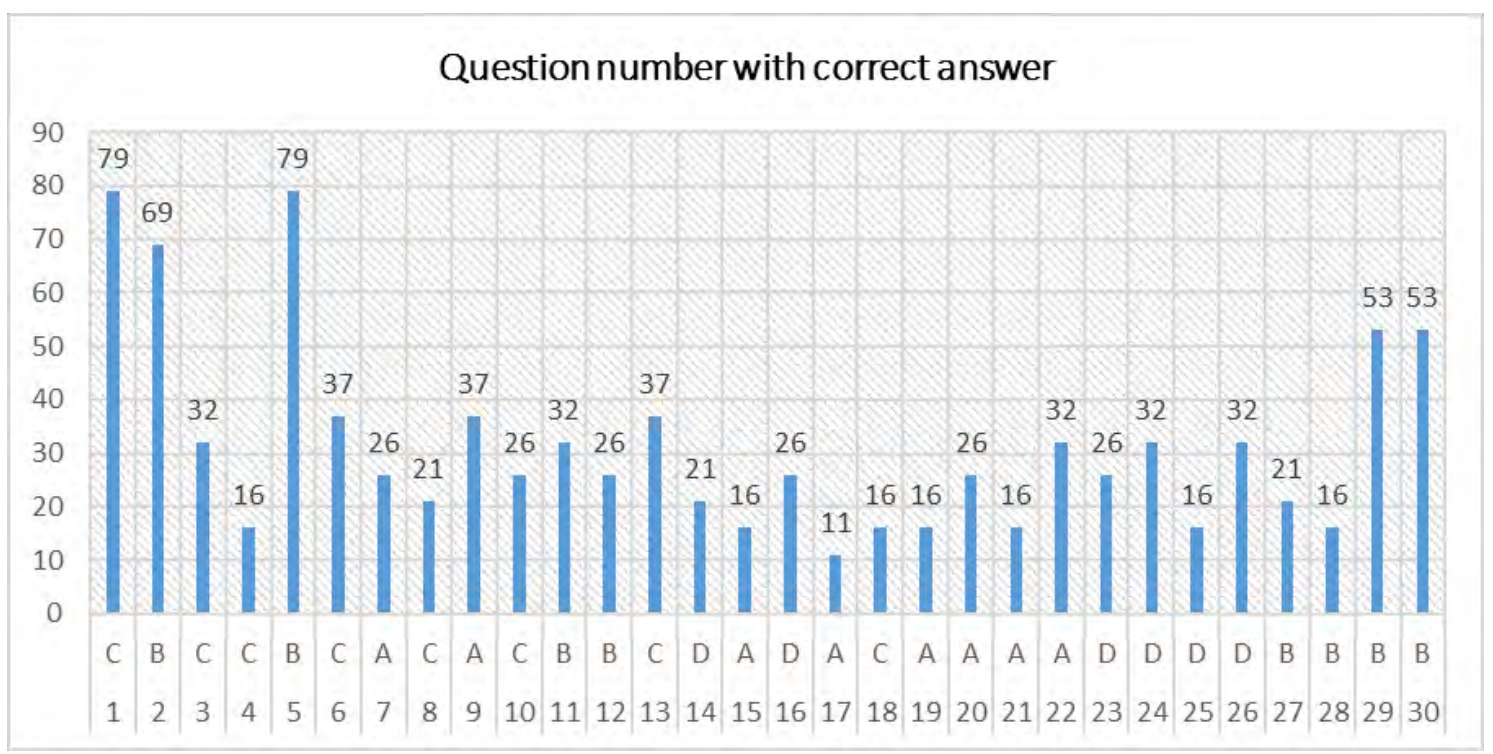

\section{Discussion}

Meaningful enhancement of human capital development requires teachers to be reflective practitioners with requisite innovative capacity and adequate pedagogical content knowledge. However, preservice teachers who participated in this empirical investigation demonstrated inadequate conceptual understanding of light phenomena. Inadequate conceptual understanding is underpinned by pervasive knowledge gaps which essentially serve to hamper teacher professional practice and meaningful enactment of innovative pedagogic approaches to demystify the complex nature of scientific phenomena. The key findings of the study revealed that preservice Physical Sciences teachers exhibited conceptual hurdles in relation to light phenomena such as reflection, refraction, total internal reflection and light scattering. The prevalence of these conceptual hurdles can partly be attributed to pervasive knowledge gaps manifested as a result of deficient instructional strategies adopted in an attempt to demystify the complex nature of light phenomena. It has been established that students tend to exhibit conceptual difficulties with virtual images even after instruction (Kaewkhong, Mazzolini \& Emarat, 2010). In addition, student misconceptions associated with plane mirrors, spherical mirrors and lenses are connected to the mode of instruction used by teachers (Kaltakci-Gurel, Eryilmaz \& Mcdermott, 2016). This study demonstrated that preservice teachers exhibited inadequate conceptual understanding of the wave and particle nature of light. In support of this notion, research has demonstrated that students find it increasingly difficult to draw a good model of the wave and particle nature of light (Özcan, 2015). There is a critical need to develop preservice teachers' conceptual understanding of complex scientific phenomena as part of their professional training with a view to enhance their professional competence and meaningful development of pedagogical content knowledge. This is certainly a significant step towards progressive realization of the improvement of the quality of science education in its broadest sense within the broader South African context. 


\section{Conclusion}

The development of preservice teachers' conceptual understanding of complex scientific phenomena is central to meaningful enhancement of their pedagogical content knowledge. Concerted efforts have to be made to ensure optimal provision of teacher professional training geared towards holistic development of teachers as reflective practitioners.

\section{References}

Kaewkhong, K., Mazzolini, A., \& Emarat, N. (2010). Thai high-school students' misconceptions about and models of light refraction through a planar surface. Physics Education, 45, 95-107.

Kaltakci-Gurel, D., Eryilmaz, A., \& Mcdermott, L. C. (2016). Identifying pre-service physics teachers' misconceptions and conceptual difficulties about geometrical optics. European Journal of Physics, 37,045705 .

Ndihokubwayo, K., Uwamahoro, J., Ndayambaje, I., \& Ralph, M. (2020). Light phenomena conceptual assessment: An inventory tool for teachers. Physics Education, 55, 035009.

Özcan, Ö. (2015). Investigating students' mental models about the nature of light in different contexts. European Journal of Physics, 36, 065042.

Sengoren, S.K. (2010). How do Turkish high school graduates use the wave theory of light to explain optics phenomena? Physics Education, 45, 253-256. 